\title{
VOLTAGE STABILITY IMPROVEMENT OF MULTI MACHINE POWER SYSTEM USING TCSC WITH REDUCED CONGESTION
}

\author{
P.Kalaimani ${ }^{1}$ and K.Mohana Sundaram ${ }^{2}$
}

\begin{abstract}
In the present power system environment, enhancing the transient stability of power system and improving the transmission capability of multi machine power system with reduced congestion of transmission line is a predominant concern of electrical engineers. Various intelligent techniques have been introduced to enhance the transient stability of the system. One such technique gaining more importance in enhancing the stability and power transfer capability of the power system is flexible alternating current transmission system (FACTS).Thyristor controlled series compensator (TCSC) is a series connected FACTS device used for real power flow control. In the system considered, TCSC uses PI controller thereby achieving the combined advantages of each controller. The designed combination of controller is tested using IEEE 9 bus test system using MATLAB/SIMULINK software. The Simulation results obtained using different combination of controller with TCSC shows the new design delivers an excellent and fast realization compared to other types.

Keywords: congestion management, FACTS, Voltage Stability TCSC, PI, PID.
\end{abstract}

\section{INTRODUCTION}

Maintaining power system stability and reliability in the existing scenario is a crucial challenge for power engineers as the demand is increasing at a faster rate day by day. The introduction of flexible alternating current transmission system made less difficult for the power engineers as the FACTS devices are more demanding in improving the transient stability and power transfer capability of the transmission line with reduced congestion. Improving the transient stability of the power system is an important issue for electrical engineers as the disturbances are more. The power system is restructured and thus the private parties are now participating in the power production. Due to participation of private parties, the transmission line loading limit becomes more crucial as the participants tries to sell their power through the transmission line. The transient stability of the system is solved by using local fuzzy based damping controller using mat lab simu link program [1].The fractional order PID controller based TCSC is introduced to improve the transient stability by combining with the integral AGC to improve the reliability [2].Transient stability analysis is performed under several cases like optimal placement of TCSC to solve transient problem using particle swarm optimization technique [3]. An active power sensitivity approach is introduced to place the TCSC optimally with a coordinated design of PSS [4]. The flexible alternating current transmission system device TCSC is used to maintain the transient stability of the system using bacterial foraging algorithm [5].The FACTS device TCSC is designed, modelled and tuned using differential algorithm to solve the transient stability problems using MAT LAB simulink software [6].A real time voltage monitoring method is introduced by using FFBPN and the weak lines are indentified and TCSC is placed in the particular lines to improve voltage Stabilty[7]. TCSC is placed in an optimal location with UPFC and wind generator to improve the profit in deregulated power system[8].The Performance of the Power System is improved by a new gravitational technique based TCSC to improve voltage stability of the system [9].The voltage stability improvement is enhanced using FACTS device by identifying the optimal location for shunt and series devices [10].

\section{THYRISTOR CONTROLLED SERIES CAPACITOR (TCSC)}

The simplified representation of elementary Thyristor-Controlled-Series-Capacitor is presented in figure 1. A

\footnotetext{
${ }^{1}$ Department of Electrical and Electronics Engineering Anna University, Chennai Tamil Nadu India

${ }^{2}$ Department of Electrical and Electronics Engineering Vel Tech MultiTech Dr.Rangarajan Dr.Sakunthala Engineering College, Chennai, Tamil Nadu,India
} 
ripple less adjustable series-capacitive reactance is obtained by paralleling series compensating capacitor with Thyristor-controlled Reactor which forms the basic construction of TCSC. Thyristor Controlled Reactor (TCR) is bridged opposite to a series capacitor. In a practical TCSC circuit, primitive compensators may be connected in series to fetch the required voltage rating and operating characteristics. The inductive-reactance of the transmission line is compensated by optimally locating TCSC, thus reducing the exchange- reactance between the overloaded buses of the transmission system. to improve the power transfer capability of the power transmission system.

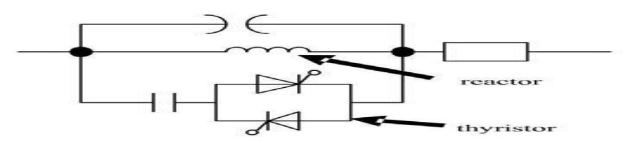

Figure 1. Equivalent circuit of TCSC

In this paper FACTS device is utilized to reduce congestion and improve the power flow capacity of the system

\subsection{Modelling of tcsc}

Various types of FACTS devices are employed to solve congested condition in transmission line and to enhance the voltage stableness of power system. In this paper Thyristor-Controlled-Series-Compensator is introduced for enhancing the voltage stability of the system. An elementary representation of transmission line is shown in figure1.It consist of two buses represented by the notation, bus-a and bus-b. The voltages-of two-buses are represented as $V_{a} \angle \delta_{a}$ and $\mathrm{V}_{\mathrm{b}} \angle \delta_{b}$. The real power flow between the two buses are mathematically represented as

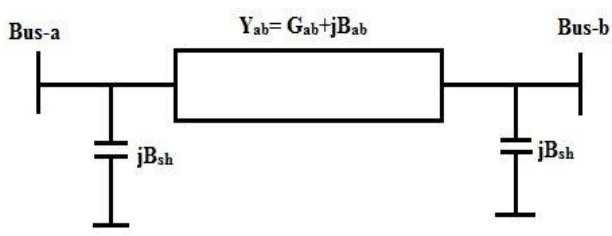

Figure 2. Elementary model of transmission line

$$
P_{a b}=V_{a}^{2} G_{a b}-V_{a} V_{b}\left[G_{a b} \cos \left(\delta_{a b}\right)+B_{a b} \operatorname{Sin}\left(\delta_{a b}\right)\right]
$$

Where $\delta_{a b}=\delta_{a}-\delta_{b}$.

Similarly the true power flow from bus-a to bus-b $\left(P_{b a}\right)$ is
\[ P_{b a}=V_{b}^{2} G_{a b}-V_{a} V_{b}\left[G_{a b} \cos \left(\delta_{a b}\right)+B_{a b} \operatorname{Sin}\left(\delta_{a b}\right)\right] \] (2)

The elementary representation of transmission line with incorporating TCSC between two buses bus-a and bus-b is shown in figure 2 .

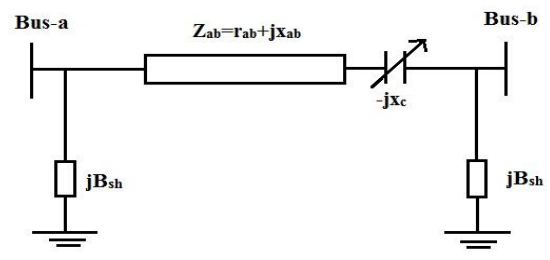

Figure 3. Model of TCSC

At stable condition of the power system network, the TCSC is considered as fixed reactance $-j x_{c}$. The real power flow from bus-a to bus-b $\left(P_{a b}^{k}\right)$ and from bus-b to bus-a $\left(P_{b a}^{k}\right)$ of the transmission line with series impedance $Z_{a b}=r_{a b}+j x_{a b}$ and series reactance $-j x_{c}$ are represented as

$$
P_{a b}^{K}=V_{a}^{2} G_{a b}^{\prime}-V_{a} V_{b}\left[G_{a b}^{\prime} \cos \left(\delta_{a b}\right)+B_{a b}^{\prime} \operatorname{Sin}\left(\delta_{a b}\right)\right]
$$




$$
P_{b a}^{K}=V_{b}^{2} G_{a b}^{\prime}-V_{a} V_{b}\left[G_{a b}^{\prime} \cos \left(\delta_{a b}\right)+B_{a b}^{\prime} \operatorname{Sin}\left(\delta_{a b}\right)\right]
$$

Where,

$$
\frac{r_{a b}}{r_{a b}^{2}+\left(x_{a b}-x_{c}\right)^{2}}
$$

and

$$
B_{a b}^{\prime}=\frac{-\left(x_{a b}-x_{c}\right)}{r_{a b}^{2}+\left(x_{a b}-x_{c}\right)^{2}}
$$

The abnormal power flow conditions in the transmission line due the presence of series capacitance effect can be compensated by infusing more (complex) power to the transmission line at sending end $\left(S_{a c}\right)$ and receiving end $\left(S_{b c}\right)$ without series capacitance. It is designed as power injection model of TCSC as shown in figure 3.The power flows mathematical notations are represented as

$$
\begin{aligned}
& P_{a c}=P_{a b}-P_{a b}^{c}=V_{a}^{2} \Delta G_{a b}-V_{a} V_{b}\left[\Delta G_{a b} \operatorname{Co} \delta_{a b}+\Delta B_{a b} \operatorname{Sin} \delta_{a b}\right] \\
& P_{b c}=P_{b a}-P_{b a}^{c}=V_{b}^{2} \Delta G_{a b}-V_{a} V_{b}\left[\Delta G_{a b} \operatorname{Co} \delta_{a b}+\Delta B_{a b} \operatorname{Sin} \delta_{a b}\right]
\end{aligned}
$$

Where

$$
\Delta G_{a b}=\frac{x_{c} r_{a b}\left(x_{c}-2 x_{a b}\right)}{\left(r_{a b}^{2}+x_{a b}^{2}\right)\left(r_{a b}^{2}+\left(x_{a b}-x_{c}\right)^{2}\right)}
$$

and

$$
\Delta B_{a b}=\frac{-x_{c}\left(r_{a b}^{2}-x_{a b}^{2}+x_{c} x_{a b}\right)}{\left(r_{a b}^{2}+x_{a b}^{2}\right)\left(r_{a b}^{2}+\left(x_{a b}-x_{c}\right)^{2}\right)}
$$

\section{SIMULATION RESULTS}

The case study of IEEE nine bus test system without TCSC is modelled and simulated using mat lab. . An additional load is being added to bus-6 using a switch. The additional load is a sudden disturbance to the circuit which affects the voltage, real power and reactive power at bus-6 The waveforms for output voltage, real power and reactive power at bus 6 is obtained by Simulation

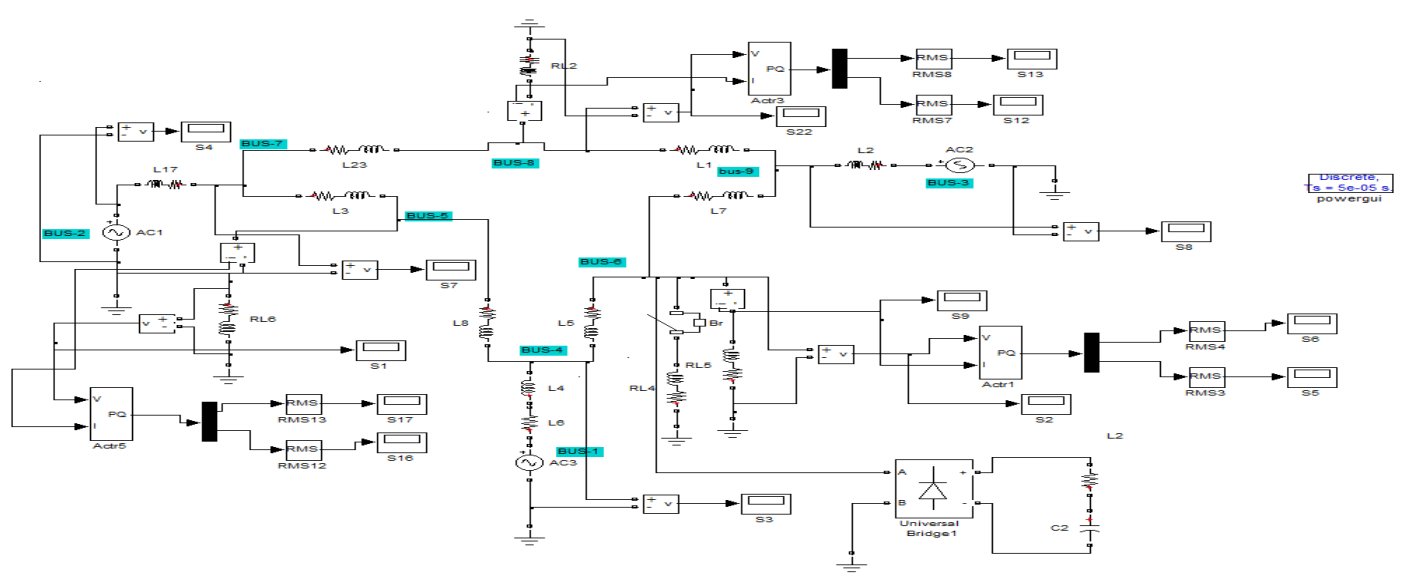

Figure 4. Nine bus system without TCSC 


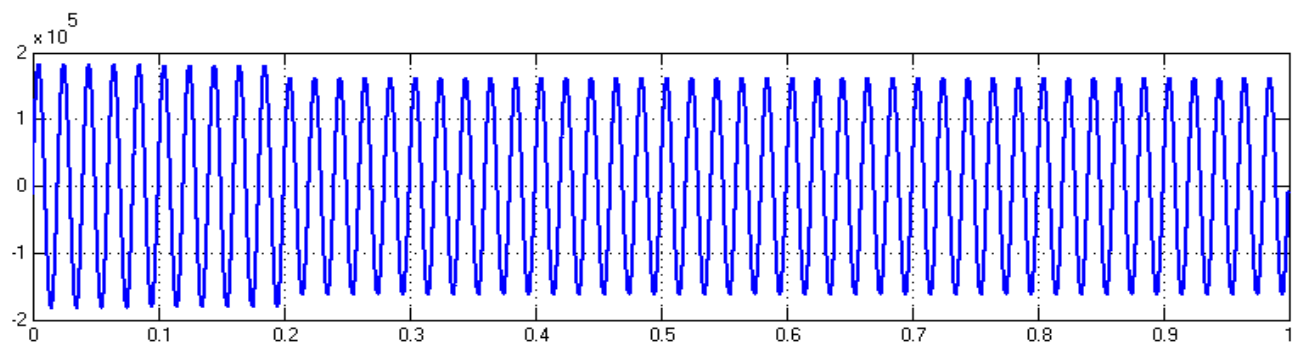

Figure 5. Output voltage at bus 6 without TCSC

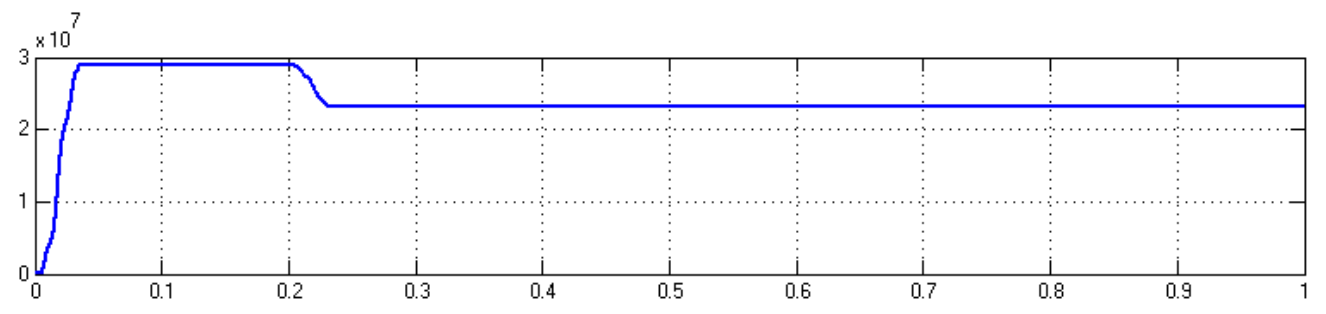

Figure 6. Real power at bus 6 without TCSC

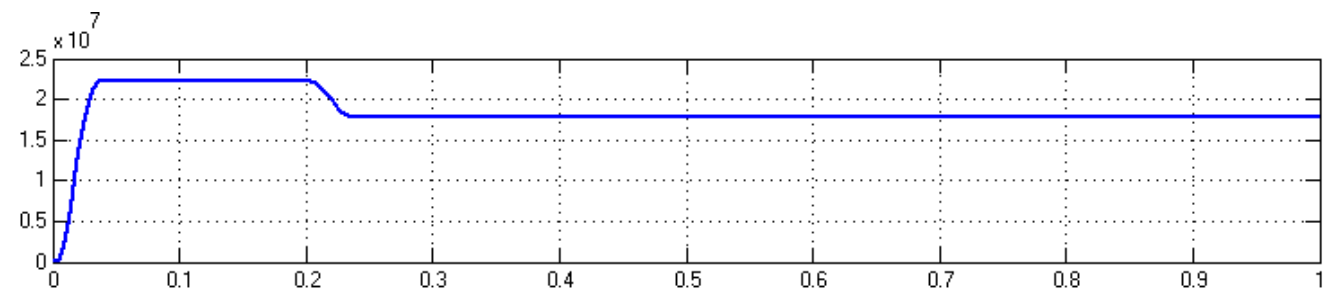

Figure 7. Reactive power at bus 6 without TCSC

The output voltage at bus 6 is 162 kilovolts. The real and reactive power at bus 6 is found to be 25.45 megawatts and 17.25 megawatts respectively.

\subsection{Nine Bus System With TCSC :}

The case study of IEEE nine bus test system with TCSC controller is presented in this section. The FACTS device TCSC is connected between bus 5 and bus 6 were an additional load is given. The waveforms of voltage , real and reactive power at load bus 6 is obtained by simulation.

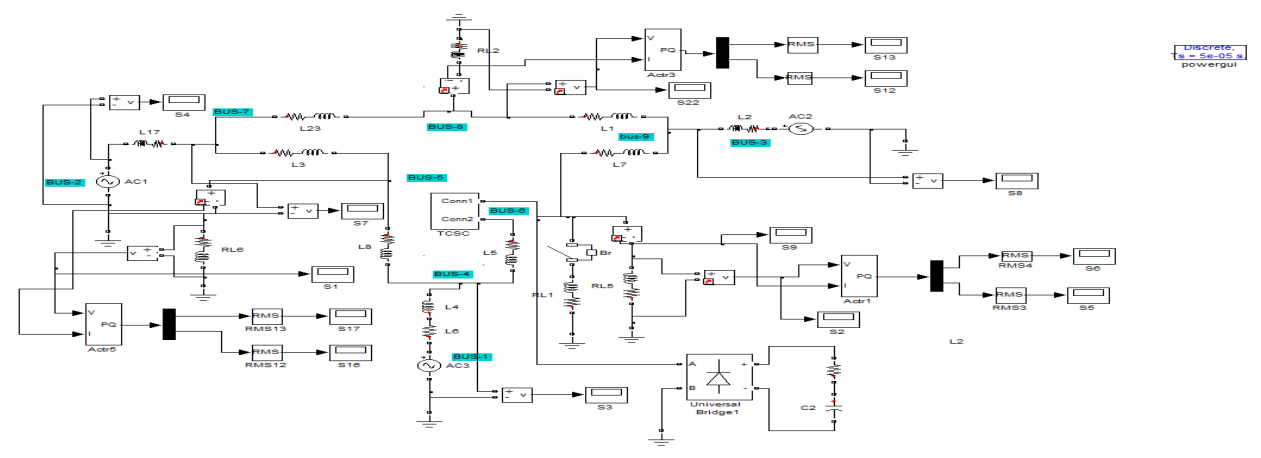

Figure 8. Ninebus system with TCSC 


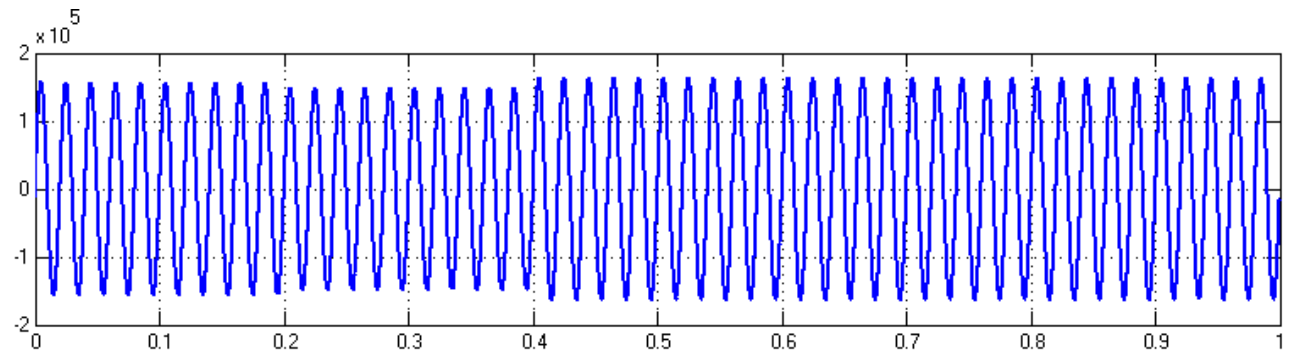

Figure 9. Output voltage at bus 6 with TCSC

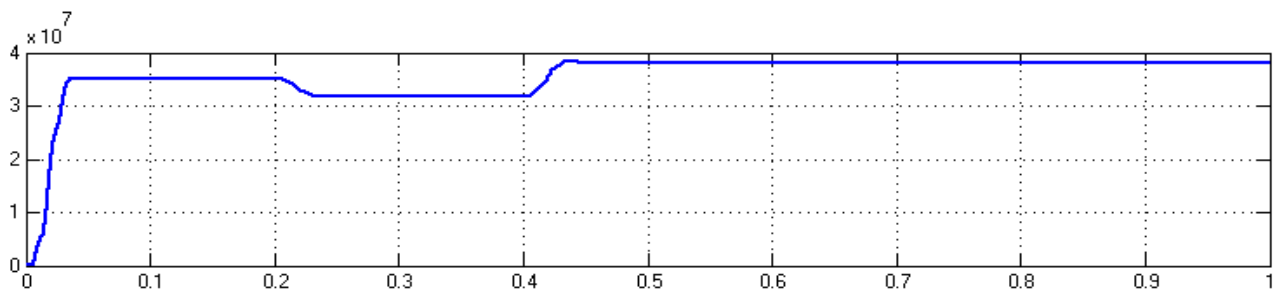

Figure10. Real power at bus 6 with TCSC

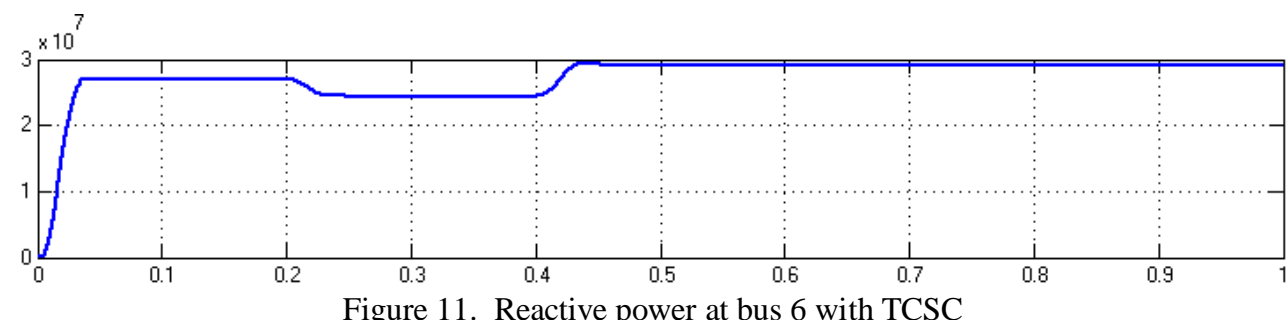

The output voltage at bus 6 is 175 kilovolts. The real and reactive power at bus 6 is 38.05 megawatts and 28.60 megawatts respectively. The cumulative results of the real power, reactive power and load bus voltage observed from the waveforms are summarized in table 1 and table 2 respectively.

Table 1. Real power \& Reactive power at bus 6

\begin{tabular}{|c|c|c|c|c|}
\hline Bus No & $\begin{array}{l}\text { Real power } \\
\text { (MW) } \\
\text { Without } \\
\text { TCSC }\end{array}$ & $\begin{array}{l}\text { Real power } \\
\text { (MW) } \\
\text { With } \\
\text { TCSC }\end{array}$ & $\begin{array}{l}\begin{array}{l}\text { Reactive } \\
\text { power }\end{array} \\
\text { (MVAR) } \\
\text { Without } \\
\text { TCSC }\end{array}$ & $\begin{array}{l}\text { Reactive } \\
\text { power } \\
\text { (MVAR) } \\
\text { With TCSC }\end{array}$ \\
\hline Bus6 & 25.45 & 38.05 & 17.25 & 28.60 \\
\hline
\end{tabular}

Table 2 Load voltage at bus 6

\begin{tabular}{|l|l|l|}
\hline \multirow{3}{*}{ Bus No } & Voltage & Voltage \\
& $(\mathrm{KV})$ & $(\mathrm{KV})$ \\
& without TCSC & with TCSC \\
\hline
\end{tabular}




\begin{tabular}{|l|l|l|}
\hline Bus-6 & $162 \mathrm{kv}$ & $175 \mathrm{kv}$ \\
\hline
\end{tabular}

\subsection{Nine Bus System With Closed Loop TCSC And PI Controller :}

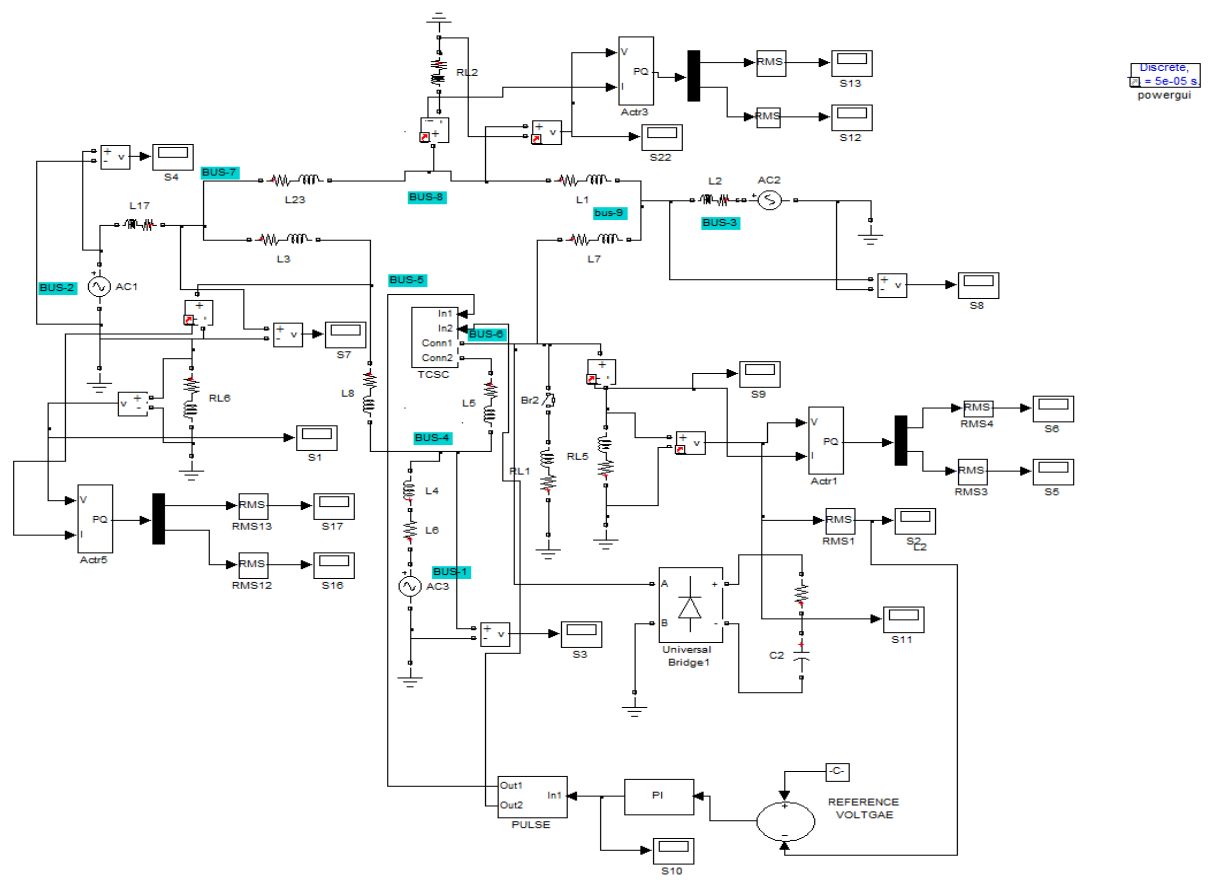

Figure 12 Closed loop system with PI controller

The performance of the system is further improved by connecting PI controller with TCSC.The wave forms of Voltage at bus 6 , the real power and reactive power of the system at bus 6 are shown below.

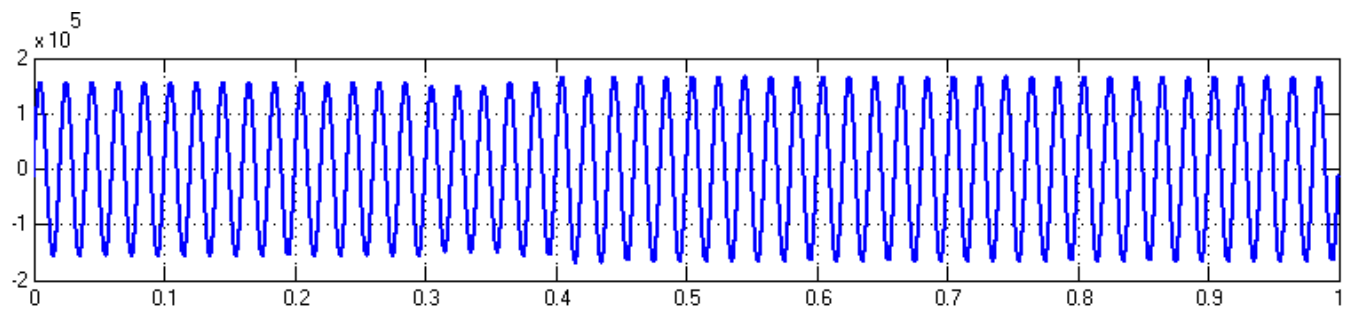

Figure 13. Output voltage at bus 6

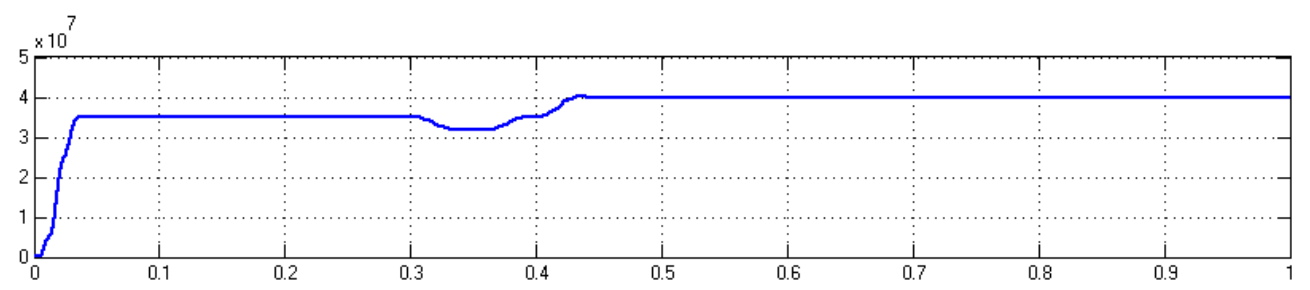

Figure 14. Real power at bus 6 


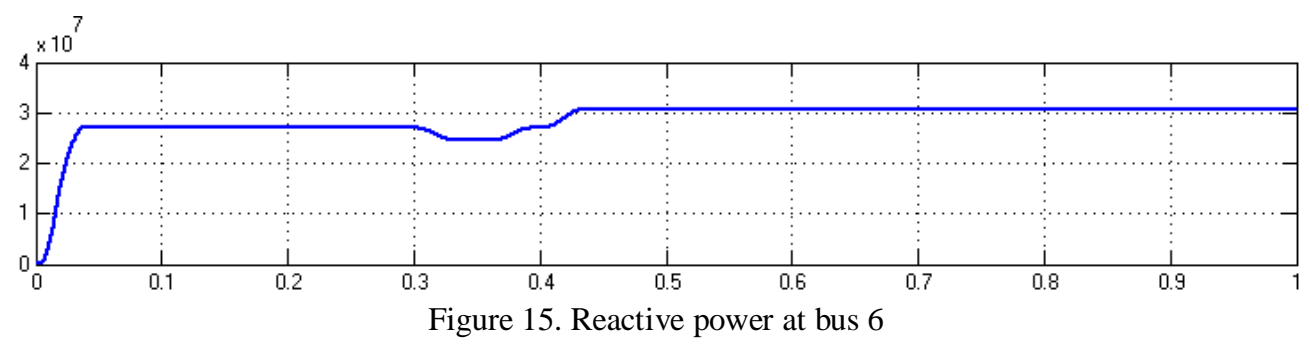

\section{CONCLUSION}

Nine bus system has been simulated with and without TCSC to observe its performance. It is clear that the real power transmitted with TCSC is higher than without TCSC. The FACTS device TCSC is implemented as it is cheaper than other FACTS devices such as UPFC and IPFC. It is observed that TCSC is more suitable to reduce transmission congestion and to control the power through the transmission line. The disadvantage of TCSC is that it introduces current harmonics into the transmission line. The nine bus system has also been simulated with TCSC for PI controller to observe its time domain specification.. The scope of the present work is to improve the transient stability and time domain specifications in nine bus system. The present work will be extended to PID controller and fuzzy controller and the results will be compared.

\section{REFERENCES}

[1] Mohsen Bakhshi, Mohammad Hosein Holakooie, Abbas Rabiee. Fuzzy based damping controller for TCSC using local measurements to enhance transient stability of power systems. Electr Power Energy Syst 2017;85:12-21.

[2] Javad Morsali, Kazem Zare, Mehrdad Tarafdar Hagh. Applying fractional order PID to design TCSCbased damping controller in coordination with automatic generation control of interconnected multisource power system. Eng. Sci. Technol., Int. J. 20 (2017) 1-17.

[3] S.K.Rautray a , S.Choudhury a , S.Mishra a , P.K.Rout "A Particle Swarm Optimization Based Approach For Power System Transient Stability Enhancement With TCSC" 2nd International Conference on Communication, Computing \& Security [ICCCS-2012], Procedia Technology 6 ( 2012 ) $31-38$.

[4] Hamed Hasanvand, , Mohammad R. Arvan, Babak Mozafari, Turaj Amraee, "Coordinated design of PSS and TCSC to mitigate interarea oscillations," Electr Power Energy Syst 2016;78:194-206.

[5] E.S. Ali, S.M. Abd-Elazim. "TCSC damping controller design based on bacteria foraging optimization algorithm for a multimachine power system” Electr Power Energy Syst 2012;37:23-30

[6] Sidhartha Panda, Differential evolutionary algorithm for TCSC-based controller design, Simulation Modelling Practice and Theory 17 (2009) 1618-1634

[7] V. Jayasankar , N. Kamaraj, N. Vanaja, "Estimation of voltage stability index for power system employing artificial neural network technique and TCSC placement" Neurocomputing, Vol. 73, No. 16-18, pp. 3005-3011, October, 2010.

[8] Subhojit Dawn, Prashant Kumar Tiwari , "Improvement of economic profit by optimal allocation of TCSC \& UPFC with wind power generators in double auction competitive power market" Electr Power Energy Syst 2016;80:190-201.

[9] Mahmoud A. Attia, Hany M. Hasanien, Almoataz Y. Abdelaziz, "Performance enhancement of power systems with wave energy using gravitational search algorithm based TCSC devices" Engineering Science and Technology, an International Journal ,Volume 19, Issue 4, December 2016, Pages 16611667.

[10] Priti Prabhakar, Ashwani Kumar, "Voltage stability boundary and margin enhancement with FACTS and HVDC" Electr Power Energy Syst 2016; 82:429-438. 